CLINICAL STUDY

\title{
Comparison of the effects of primary somatostatin analogue therapy and pituitary adenomectomy on survival in patients with acromegaly: a retrospective cohort study
}

Fausto Bogazzi, Annamaria Colao ${ }^{1}$, Giuseppe Rossi ${ }^{2}$, Martina Lombardi, Claudio Urbani, Chiara Sardella, Aldo Iannelli ${ }^{3}$, Ilaria Scattina, Luca Manetti, Simone Del Sarto ${ }^{2}$, Rosario Pivonello ${ }^{1}$, Ludovica Francesca Stella Grasso ${ }^{1}$, Isabella Lupi, Renata Simona Auriemma ${ }^{1}$, Gaetano Lombardi ${ }^{1}$ and Enio Martino

Section of Endocrinology, Department of Clinical and Experimental Medicine, University of Pisa, Ospedale Cisanello, Via Paradisa 2, 56124 Pisa, Italy, ${ }^{1}$ Department of Molecular and Clinical Endocrinology and Oncology, University Federico II, Naples, Italy, ${ }^{2}$ Unit of Epidemiology and Biostatistics, Institute of Clinical Physiology, National Research Council, Pisa, Italy and ${ }^{3}$ Department of Neurosciences, University of Pisa, Pisa, Italy

(Correspondence should be addressed to F Bogazzi; Email: fausto.bogazzi@med.unipi.it)

\begin{abstract}
Objective: Acromegalic patients have an increased risk of mortality. The objective of this study was to compare the effect of different therapies for acromegaly on mortality.

Design and methods: The mortality rate of 438 consecutive acromegalic patients was compared with that of the general population using the standardized mortality ratio (SMR); the effect of different therapies on survival was evaluated using Cox regression analysis.

Results: Twenty patients (4.5\%) died between 1999 and 2009. Age- and sex-adjusted SMR was 0.70 (95\% CI 0.43-1.08). The Cox regression analysis revealed that, in the whole population, both general risk factors (age and physical status) and specific factors for acromegaly (macroadenoma, hypopituitarism and uncontrolled disease) were associated with death. The most compromised patients at diagnosis had a higher mortality rate $(P=0.001)$, which also occurred in patients with controlled acromegaly. Death occurred in 2.4\% (adenomectomy), 2.6\% (adenomectomy followed by somatostatin analogue (SSA) therapy) and 11.4\% (SSA therapy as the primary therapy) of the patients. The risk of death was higher in patients receiving SSA therapy as the primary therapy (hazard ratio $(\mathrm{HR}) 5.52,95 \% \mathrm{CI} 1.06-28.77, \mathrm{P}=0.043)$ than in all patients submitted to adenomectomy; however, a higher risk of death occurred only in diabetic patients treated with SSAs alone (HR 21.94, 95\% CI 1.56-309.04, $P=0.022$ ). Radiotherapy was associated with an increased risk of mortality, which occurred in patients with the more locally advanced disease.

Conclusions: Therapies for acromegaly and comorbidities have lowered the risk of mortality to the level of the general population; the effect of SSA therapy alone or that following pituitary adenomectomy was comparable to that of curative neurosurgery on survival in non-diabetic patients; on the contrary, SSA therapy as the primary therapy may be less effective than adenomectomy in reducing mortality rate in diabetic patients.
\end{abstract}

European Journal of Endocrinology 169 367-376

\section{Introduction}

Acromegaly is a rare disease with unrestricted secretion of GH-insulin-like growth factor 1 (IGF1) leading to an increased prevalence of comorbidities, including arterial hypertension, diabetes mellitus, cardiomyopathy, abnormalities of pulmonary function and tumours, which are responsible for a higher mortality rate than that found in the general population $(1,2,3,4,5,6,7$, $8,9,10,11,12,13,14,15,16)$. Older studies have reported a standardized mortality rate (SMR) of up to 3.31, meaning that patients with acromegaly had more than a $300 \%$ increased risk of mortality than the general population (6). Although the SMR decreased from 3.31, for patients studied in the 1960s (6), to 1.26, for those studied in the 1990s (11) or to 1.16 , when older patients were excluded from the analysis (1), global SMR remained higher than that in the general population. Two recent meta-analyses, which analysed studies published from 1970 to 2007 (14, 15), have reported an overall increased mortality rate of $70 \%$. Thus far, only pituitary adenomectomy alone or combined with external radiotherapy or somatostatin analogue (SSA) therapy has been reported to reduce mortality rate in acromegaly, but a comparison among therapies is lacking $(14,15)$.

Studies have reported that the risk of mortality approached that of the general population when disease 
was controlled or cured $(1,9,11,13)$; in contrast, previous external radiotherapy of the pituitary region $(11,16,17)$ and hypoadrenalism $(16,17)$ have been reported to be associated with an increased risk of mortality. Thus far, only specific factors related to acromegaly have been reported to be the predictors of mortality, whereas the impact of common risk factors of death in the general population (i.e. comorbidities) is unknown. When SSAs were employed in the treatment of acromegaly, disease control was achieved, on average, in two-third of the patients, leading to the improvement of several parameters, including cardiac function and vascular abnormalities (2). However, data detailing the effect of SSA therapy as the primary therapy, which has been proposed as an alternative to pituitary neurosurgery (18), on the mortality of patients with acromegaly are not available.

The aim of this study was to evaluate SMR and the effect of therapy with SSAs either as first-line therapy or as adjuvant to adenomectomy on the survival of patients with acromegaly in comparison with that of curative pituitary adenomectomy.

\section{Subjects and methods}

\section{Study design and patients}

We performed a retrospective cohort study, conducted using anonymized patient records, approved by the Internal Review Board at each University. It is the policy at each University Centre to obtain written informed consent for the use of anonymized data for research purpose at the first admission of each patient.

The study population was retrospectively identified and consisted of 438 consecutive patients diagnosed with acromegaly at the Department of Clinical and Experimental Medicine, University of Pisa $(n=218,137$ women, mean age $46.07 \pm 12.68$ years) or at the Department of Molecular and Clinical Endocrinology and Oncology, University Federico II, Naples $(n=220$, 112 women, mean age $43.08 \pm 13.35$ years), during the period 1966-2009. Detailed information on the clinical and biochemical data of patients, although retrospectively obtained from clinical records, was prospectively collected during the whole follow-up period; in fact, after the first diagnosis of acromegaly, all patients were followed up in the two centres, either as inpatients or as outpatients, on average, every 6 months. Life status on 31st December 2009 was ascertained by a phone interview or the cause of death as reported on the death certificate. In addition, because patients were periodically treated in our centres, the cause of death was also determined by data registered in the clinical record.

The study period encompassed the years 1966-2009, with a mean follow-up period of $11.6 \pm 7.9$ years (range 0.5-43.0 years). Deaths occurred during the period
1999-2009 and were compared with those of the Italian general population obtained from mortality tables of the ISTAT (National Institute of Statistics) for the corresponding period, 1999-2009 (http://www. istat.it/).

The diagnosis of acromegaly was made according to clinical and laboratory features, as reported earlier $(19,20)$. The cure of acromegaly after pituitary adenomectomy was defined by suppressed $\mathrm{GH}$ values after oral glucose tolerance test (OGTT) and ageadjusted normal IGF1 concentrations; in case of discrepant results, i.e. unsuppressed GH and normal IGF1 values $(n=3)$, the metabolic status of the patients was re-evaluated after 6 months; if discrepancies persisted, decision was made on the basis of the IGF1 value; a $\mathrm{GH}$ value below $1 \mu \mathrm{g} / \mathrm{l}$ during the OGTT was considered suppressed during the period 1997-2009; during the first 1990s, a GH value below $2 \mu \mathrm{g} / \mathrm{l}$ was considered suppressed; during the 1980s, a GH value below $5 \mu \mathrm{g} / \mathrm{l}$ was considered suppressed. Control of acromegaly during medical therapy was defined by normal age-adjusted serum IGF1 concentrations (20). Delay in the diagnosis of acromegaly was expressed in years, and it represents the time between the onset of symptoms and the diagnosis of acromegaly.

Treatment groups During the study period, available therapies for patients with acromegaly changed. For example, radiotherapy was used in about $30 \%$ of the patients during the decade 1970-1979, but only in $2 \%$ in the last decade of the study period; during the last two decades, a similar proportion of patients were treated with surgery or primary medical therapy, whereas most patients $(45 \%)$ were submitted to pituitary adenomectomy in the 1980s. The choice of therapy for acromegaly, for each patient, was based on clinical grounds, available treatments during that period and willingness of the patient and was independent of the purpose of the present study.

Based on the different therapies received over the study period, the patients were divided as follows: i) pituitary adenomectomy $(n=124)$; ii) pituitary adenomectomy followed by external radiotherapy and/or SSA therapy $(n=151)$ and iii) primary medical therapy with SSAs $(n=88)$. The remaining 75 patients received various therapy combinations from among the following: pituitary adenomectomy, dopamine agonists, pegvisomant, SSAs and radiotherapy, and could not be grouped for statistical analysis.

\section{Endocrine evaluation}

GH and IGF1 values were available as follows: 95.6 and $91.5 \%$ respectively at diagnosis; 97.2 and $98.6 \%$ respectively at the last clinical visit; and 93.1 and $90.9 \%$ respectively both at diagnosis and at the last clinical visit. The median time of the last clinical visit was 5.9 months. GH concentration and IGF1 index (the ratio of 
the measured IGF1 concentration to the upper value for the age) at the last clinical visit were considered, as reported previously $(11,13)$. The IGF1 index was adopted to account for variations in IGF1 measurements by different methods across the study period. Serum IGF1 concentrations for 198 patients were available at yearly intervals throughout the study period. The mean IGF1 index of the period correlated with that at the last clinical visit (intra-class correlation $0.87,95 \%$ CI $0.83-0.90, P=0.000)$, suggesting that the IGF1 index at the last clinical visit is a reliable marker of disease activity.

During the 1980s, GH concentration was measured using the HGHK-2 RIA (Sorin Biomedica, Saluggia, Italy); during the 1990s, it was determined using the HGH kit (Nichols Institute Diagnostic, San Juan Capistrano, CA, USA). During the last 7 years, GH concentration has been measured using an automated Advantage Chemiluminescent GH Assay (DiaSorin S.p.A., Saluggia, Italy).

Serum IGF1 concentration was measured using an IRMA (Nichols Institute Diagnostic) until 2005 and was then measured using an automated RIA (DIAsource ImmunoAssays S.A., Nivelles, Belgium).

Hypopituitarism was defined by at least one proven pituitary hormone deficit; central hypoadrenalism was identified by a reduced response to the ACTH stimulatory test; central hypothyroidism was defined by serum thyroxine concentrations below the normal range in the presence of normal or low TSH concentrations; central hypogonadism was defined by low testosterone levels and low gonadotrophin concentrations in men, by low gonadotrophin concentrations in the presence of normal prolactin levels in amenorrheic women or by low FSH concentrations in postmenopausal women. Hormone replacement therapy was given as appropriate.

\section{Evaluation of comorbidities and severity of disease}

For many years, both the centres had employed a similar protocol to evaluate systemic complications of acromegalic patients (2). Briefly, all acromegalic patients were examined by complete colonoscopy, colour Doppler echocardiography, measurement of arterial pressure, and measurement of blood cholesterol and glucose concentrations and assessed for respiratory function at diagnosis. These parameters were re-evaluated almost every year, except for colonoscopy, which was repeated every $3-5$ years depending on the findings of the first examination.

The definition of comorbidities, at the diagnosis of acromegaly, was based on the criteria of the corresponding period; during the most recent years, arterial hypertension has been defined by the 2007 ESH-ESC guideline criteria (21), left ventricular (LV) hypertrophy by LV mass exceeding normal values, LV diastolic dysfunction by higher-than-normal E/A or lower-than- normal isovolumetric relaxation time (IVRT), diabetes mellitus and impaired glucose tolerance by the WHO consultation recommendations (22). The cardiovascular risk at diagnosis and at the last clinical visit was evaluated as reported previously (23).

When revealed at colonoscopy, colonic lesions were removed; arterial hypertension, diabetes mellitus and common risk factors of cardiac and cerebrovascular disease were treated accordingly; sleep apnoea was treated using a continuous positive air pressure apparatus.

The physical status of each patient was evaluated, at the diagnosis of acromegaly, using the American Society of Anaesthesiologists (ASA) Physical Status scoring system (24): Class 1, normal healthy patient; Class 2, patient with mild systemic disease; Class 3, patient with severe systemic disease; Class 4, patient with severe, life-threatening systemic disease; Class 5, moribund patient and Class 6 , declared brain-dead patient. Patients in Classes 1 and 2 were grouped owing to a low mortality risk similar to that in the general population in keeping with previous reports (25). No Class 5 patients were identified in our patient cohort. Thus, for assessing mortality, three groups (ASA 1-2, ASA 3 and ASA 4) were considered.

\section{Statistical analysis}

Data are expressed as means \pm s.D. for continuous variables and as a percentage for qualitative variables.

To compare mortality rates during the period 19992009 between the patient cohort and the general population, a mortality ratio standardized for sex, age and calendar period (SMR) was calculated as the ratio of observed deaths to the number of expected deaths, based on the person-years follow-up for each sex, age and calendar period group of the patient cohort for the corresponding period. The expected number was estimated by multiplying age-, sex- and calendar period-specific death rates in the general population of Italy by the person-years at risk accumulated within the age-, sex- and calendar period-specific strata corresponding to the patient cohort. An exact 95\% CI for SMR was calculated (26). Standard mortality data for the general Italian population were obtained from the Italian Statistics Institute (ISTAT, http://www.istat.it/).

Comparison of means between the groups was performed using the ANOVA test. If the homogeneity of variances was not met, Welch's ANOVA was performed. Fisher's exact test was used to test the difference between categorical variables.

Cox regression analysis was used to study the determinants of survival present at the time of diagnosis, adjusted for age. We also evaluated serum $\mathrm{GH}$ and IGF1 concentrations measured at the last clinical visit, which were analysed as continuous variables. Significant or near-to-significant covariates in the univariate Cox regression analysis were used in a multivariate Cox regression analysis to evaluate their 
independent predictive value on survival. Treatment effect was evaluated adjusting for covariates giving significant results in the Cox regression analysis. Hazard ratios (HRs) and 95\% CI were also computed. For the survival analysis, the whole study period (1966-2009) was considered. The survival time was computed as the time interval between the date of diagnosis and the date of death or 31st December 2009. GH concentration and IGF1 index were considered as continuous variables in the Cox model. The physical status of patients (ASA score) was included in the model as a categorical variable. The concordance between two continuous variables was evaluated by the intra-class correlation. A two-sided $P$ value $<0.05$ was considered to be statistically significant. SPSS for Windows version 13.0 (SPSS, Inc.) and R package 'survival' version 2.36-14 were used to perform data analysis.

\section{Ethical approval}

This was a retrospective cohort study, conducted with anonymized patient records, approved by the Internal Review Board at each University.

\section{Strobe statement}

This study was conducted and reported in accordance with the Strengthening the Reporting of Observational Studies in Epidemiology (STROBE) recommendations.

\section{Results}

A total of 438 consecutive patients (249 women, $56.8 \%$ ) were evaluated; the clinical and biochemical findings of the patients are given in Table 1. At the end of the follow-up period, in $57 \%$ patients of the whole group, control of acromegaly was achieved.

\section{Overall mortality and cause of death}

Among the 438 patients, 20 (4.5\%) died during the period 1999-2009. All-cause mortality rate was not significantly different in the overall group of patients compared with that in the general population. Age- and sex-adjusted SMR was 0.70 (95\% CI 0.43-1.08) and mean age at death was $68.8 \pm 10.8$ years. The age at death of females was $70.7 \pm 10.2$ years and that of males was $66.1 \pm 11.9$ years; the SMR of females was 0.88 (95\% CI $0.45-1.54)$ and that of males was 0.53 (95\% CI 0.23-1.05). Death was caused by acute myocardial infarction $(n=4)$ or cerebrovascular disease $(n=5)$ in nine patients, by malignant tumours (breast, gastric, biliary, hepatic, uterine or unknown origin) in six patients, by intracranial expansion of the pituitary tumour in four patients and by malnourishment in one elderly patient. No patient deaths resulted from colonic carcinoma, respiratory failure or cardiac failure. Three of the four patients with intracranial expansion of the pituitary tumour were treated with transcranial surgery (three operations in two patients and two operations in one patient) followed by external radiation therapy; the remaining patients died during the third operation for bleeding complications.

\section{General risk factors of mortality in the whole population of acromegalic patients}

In the univariate Cox regression analysis, after adjustment for age, general risk factors significantly or nearly significantly associated with mortality were age, diabetes mellitus and physical status of the patient (ASA Class) at diagnosis (Table 2).

In the multivariate Cox regression analysis, the strongest determinants of mortality were older age and the general conditions, i.e. the physical status of the patient (ASA Class 3 or 4 ) at diagnosis (Table 2).

On colonoscopy, 53 (12.1\%) precancerous lesions and $7(1.6 \%)$ colonic cancers were revealed and successfully removed; no deaths occurred due to colonic cancer. Common risk factors of cardiac or cerebrovascular disease (arterial hypertension, diabetes mellitus and hypercholesterolaemia) were detected, on average, in one-third of the patients and accordingly treated (Table 1). The cardiovascular risk profile did not significantly change at the last clinical visit with respect to the diagnosis of acromegaly (6.2 vs $6.8, P=0.153)$.

\section{Risk factors of mortality specific for acromegaly}

In the univariate Cox regression analysis, after adjustment for age, pituitary macroadenoma, and hypopituitarism, either high serum GH concentration or IGF1-index at last clinical visit was the predictive factor of mortality specific for acromegaly (Table 2). Two multivariate models (including either GH concentration or IGF1 index at the last clinical visit) were used; significant or near-to-significant predictors of mortality were IGF1 index, GH concentration, hypopituitarism and macroadenoma (Table 2).

The number of pituitary hormone deficiencies (HR $4.36,95 \%$ CI $1.49-12.77, P=0.007$, for a single deficit or $6.02,95 \%$ CI $1.54-23.62, P=0.010$, for three deficits) and hypogonadism alone (HR 5.61, 95\% CI $1.80-17.49, P=0.003)$ or associated with hypothyroidism (HR 5.15, 95\% CI 1.15-23.12, $P=0.032$ ), but not hypoadrenalism $(P=0.992)$, were associated with mortality. Among patients with hypopituitarism, ten deaths occurred, seven of which were in patients with diabetes; overall, deaths occurred in $3.6 \%$ of the nondiabetic patients and $24.3 \%$ among the diabetic patients; in addition, among patients with hypopituitarism, the proportion of macroadenomas did not differ among patients with $(82.1 \%)$ or without $(86.6 \%)$ diabetes. 
Table 1 Clinical and biochemical features of the patients.

\begin{tabular}{|c|c|c|}
\hline & Values & $\begin{array}{l}\text { Patients with available } \\
\text { information }(n)\end{array}$ \\
\hline Sex: female, $n(\%)$ & $249(56.8)$ & 438 \\
\hline Age at diagnosis (years), mean \pm s.D. & $44.7 \pm 13.1$ & 438 \\
\hline GH concentration at diagnosis $(\mu \mathrm{g} / \mathrm{l})$, mean \pm S.D. & $32.4 \pm 53.4$ & 421 \\
\hline IGF1 index at diagnosis, mean \pm S.D. & $2.6 \pm 1.1$ & 402 \\
\hline Estimated delay in diagnosis (years), mean \pm s.D. & $6.8 \pm 6.6$ & 438 \\
\hline Pituitary macroadenoma, $n(\%)$ & $299(71.0)$ & 421 \\
\hline Arterial hypertension, $n(\%)$ & $163(37.2)$ & 438 \\
\hline Diabetes mellitus, $n(\%)$ & $105(24.0)$ & 438 \\
\hline Hypercholesterolaemia, $n$ (\%) & $121(27.6)$ & 438 \\
\hline Sleep apnoea, $n(\%)$ & $33(7.6)$ & 437 \\
\hline Left ventricular hypertrophy, $n(\%)$ & 170 (41.5) & 410 \\
\hline Diastolic dysfunction, $n(\%)$ & $120(29.7)$ & 404 \\
\hline Hypopituitarism, $n(\%)$ & $127(29.0)$ & 438 \\
\hline Hypogonadism & $39(8.9)$ & \\
\hline Hypogonadism + hypoadrenalism & $11(2.5)$ & \\
\hline Hypogonadism + hypothyroidism & $17(3.9)$ & \\
\hline Hypoadrenalism & $10(2.3)$ & \\
\hline Hypoadrenalism + hypothyroidism & $2(0.5)$ & \\
\hline Hypothyroidism & $18(4.1)$ & \\
\hline Total hypopituitarism & $30(6.8)$ & \\
\hline Physical status (ASA Class) at diagnosis, $n(\%)$ & & 411 \\
\hline ASA 1 & $26(6.1)$ & \\
\hline ASA 2 & $201(48.9)$ & \\
\hline ASA 3 & $140(34.1)$ & \\
\hline ASA 4 & $44(10.7)$ & \\
\hline Pituitary adenomectomy, $n(\%)$ & $292(66.7)$ & 438 \\
\hline Second pituitary surgery, $n(\%)$ & $28(6.4)$ & 438 \\
\hline External radiotherapy, $n(\%)$ & $69(15.8)$ & 438 \\
\hline Somatostatin analogues (SSAs), $n$ (\%) & $371(84.7)$ & 438 \\
\hline Dopamine agonists ${ }^{\mathrm{a}}, n(\%)$ & $111(25.3)$ & 438 \\
\hline Pegvisomant $^{\mathrm{a}}, n(\%)$ & $56(12.8)$ & 438 \\
\hline Treatment groups, $n(\%)$ & & 438 \\
\hline Pituitary adenomectomy & $124(28.3)$ & \\
\hline Pituitary adenomectomy and SSA therapy & $151(34.5)$ & \\
\hline Primary SSA therapy & $88(20.1)$ & \\
\hline Other therapies ${ }^{b}$ & $75(17.1)$ & \\
\hline Controlled disease at the last clinical visit, $n(\%)$ & $247(57.0)$ & 433 \\
\hline
\end{tabular}

ASA, American Society of Anaesthesiologists physical status classification system ranged from 1 to 6 (25).

aThese therapies were in association with other treatments.

${ }^{b}$ Other therapies consisted of various associations among the following: pituitary adenomectomy, dopamine agonists, pegvisomant, SSAs and radiotherapy. IGF1 index was expressed as a ratio of the measured IGF1 concentration and the upper value for the age.

\section{Effect of therapies for acromegaly on survival}

Three deaths $(2.4 \%)$ occurred among patients treated with pituitary adenomectomy; four deaths $(2.6 \%)$ occurred among patients in whom neurosurgery was followed by SSA therapy; and ten deaths $(11.4 \%)$ occurred among patients treated primarily with SSAs (Table 3). Three deaths (4\%) occurred in the remaining patients receiving miscellaneous treatments.

Patients treated with SSA therapy as the primary therapy were older and more compromised (as assessed by the ASA score), with higher IGF1 values and slightly longer disease duration at diagnosis (Table 3). Thirty-six patients had ASA score 4, 15 of whom were treated with pituitary adenomectomy and the remaining 21 with primary medical therapy; death occurred in 13.3 and $33.3 \%$ of the patients treated with surgery or SSA therapy respectively; among the 116 patients with ASA score 3, 90 were submitted to surgery and 26 were given SSA therapy; death occurred in 4 and 12\% respectively. The risk of death in patients treated with primary SSA therapy was higher than that in all patients treated with pituitary neurosurgery (HR 5.52, 95\% CI 1.06-28.77, $P=0.043$; Table 4 and Fig. 1), notwithstanding appropriate correction for several covariates (age at diagnosis, macroadenoma, hypopituitarism, ASA score, arterial hypertension, diabetes mellitus, and acromegaly activity at the last clinical visit), including those which differed at baseline among the therapeutic groups. More importantly, when patients were stratified by diabetes mellitus, only diabetic patients receiving the primary therapy with SSAs had a high HR of $21.94(95 \%$ CI $1.56-309.04, P=0.022)$, whereas non-diabetic patients had a HR of 1.30 (95\% CI $0.04-$ $38.09, P=0.881)$. GH concentration or IGF1 index did not differ in diabetic $(34.7 \pm 56.7 \mu \mathrm{g} / \mathrm{l}, 2.6 \pm 1.3)$ or 
Table 2 Risk factors of mortality in univariate and multivariate Cox regression analyses. GH concentration at the last clinical visit ( $1 \mu \mathrm{g} / \mathrm{l})$; IGF1 was expressed as the IGF1 index, representing the ratio of the observed serum IGF1 concentration and the upper IGF1 limit for the age (1 unit).

\begin{tabular}{|c|c|c|c|c|c|c|}
\hline & & & \multicolumn{4}{|c|}{ Multivariate analysis } \\
\hline & \multicolumn{2}{|c|}{$\begin{array}{l}\text { Univariate analysis } \\
\text { (age-adjusted) }\end{array}$} & \multicolumn{2}{|l|}{ Model with GH } & \multicolumn{2}{|c|}{ Model with IGF1 } \\
\hline & $\mathrm{HR}(95 \% \mathrm{Cl})$ & $P$ & $\mathrm{HR}(95 \% \mathrm{Cl})$ & $P$ & $\mathrm{HR}(95 \% \mathrm{Cl})$ & $P$ \\
\hline Age at diagnosis (years) & $1.13(1.08-1.85)$ & 0.000 & $1.14(1.08-1.20)$ & 0.000 & $1.14(1.08-1.19)$ & 0.000 \\
\hline Sex (male) & $1.45(0.57-3.71)$ & 0.435 & & & & \\
\hline $\mathrm{GH}$ concentration at diagnosis $(1 \mu \mathrm{g} / \mathrm{l})$ & $0.99(0.98-1.01)$ & 0.695 & & & & \\
\hline IGF1 index at diagnosis (1 unit) & $0.76(0.50-1.17)$ & 0.214 & & & & \\
\hline Estimated delay in diagnosis (1 year) & $0.99(0.95-1.05)$ & 0.967 & & & & \\
\hline Pituitary macroadenoma & $3.17(1.04-9.68)$ & 0.042 & $3.41(0.91-12.78)$ & 0.068 & $2.72(0.85-8.76)$ & 0.093 \\
\hline Arterial hypertension & $0.48(0.19-1.21)$ & 0.121 & & & & \\
\hline Diabetes mellitus & $2.41(0.97-5.98)$ & 0.058 & $1.26(0.46-3.42)$ & 0.647 & $1.34(0.51-3.49)$ & 0.550 \\
\hline Hypercholesterolaemia & $1.71(0.48-6.07)$ & 0.408 & & & & \\
\hline Sleep apnoea & $1.05(0.24-4.59)$ & 0.951 & & & & \\
\hline Left ventricular hypertrophy & $1.82(0.57-5.87)$ & 0.131 & & & & \\
\hline Diastolic dysfunction & $2.25(0.76-6.62)$ & 0.141 & & & & \\
\hline Hypopituitarism & $4.32(1.74-10.73)$ & 0.002 & $1.56(0.52-4.62)$ & 0.426 & $2.39(0.89-6.42)$ & 0.083 \\
\hline \multicolumn{7}{|l|}{ Physical status (ASA Class) } \\
\hline ASA 3 & $7.89(0.96-64.73)$ & 0.054 & $5.22(0.61-44.95)$ & 0.133 & $4.82(0.56-41.16)$ & 0.151 \\
\hline ASA 4 & 26.14 (3.34-204.63) & 0.002 & $15.33(1.82-128.96)$ & 0.012 & $12.61(1.47-107.96)$ & 0.021 \\
\hline $\begin{array}{l}\text { GH concentration at the last clinical } \\
\text { visit }(\mu \mathrm{g} / \mathrm{l})\end{array}$ & $1.04(1.02-1.06)$ & 0.000 & $1.03(1.01-1.06)$ & 0.005 & & \\
\hline IGF1 index at the last clinical visit (unit) & $1.78(1.09-2.89)$ & 0.020 & & & $1.90(1.19-3.05)$ & 0.008 \\
\hline
\end{tabular}

ASA, American Society of Anaesthesiologists physical status classification system ranged from 1 to 6 (24); ASA was categorized as $\leq 2$, 3 and 4 . HR, hazard ratio.

non-diabetic $(34.6 \pm 57.3 \mu \mathrm{g} / \mathrm{l}$ and $2.6 \pm 1.1)$ patients; likewise, the proportions of in diabetic and nondiabetic patients controlled acromegaly were similar (52 vs $59 \%$ ).

Radiotherapy was used as a second-line therapy in patients with persistent disease after pituitary adenomectomy; among the operated patients, those irradiated had an increased mortality risk assessed by either the univariate (HR 8.03, 95\% CI 1.32-48.89, $P=0.024)$ or multivariate (HR, 34.25, 95\% CI 1.42824.93, $P=0.030)$ analysis. Radiotherapy was employed in four of $62(6.4 \%)$ patients with microadenoma and in 49 of $221(22.2 \%)$ patients with macroadenoma $(P=0.005)$; all deceased patients among those submitted to neurosurgery $(n=7)$ had pituitary macroadenoma, five of whom were irradiated.

\section{Discussion}

The results of this study showed that i) overall, therapies for acromegaly associated with treatment of its major comorbidities lowered the risk of mortality to the level of the general population and ii) SSA therapy was less effective than pituitary adenomectomy in reducing the risk of death in patients with diabetes mellitus.

The rate and causes of death in this cohort of acromegalic patients did not differ from those in the general population (cardiac or cerebrovascular disease or tumours), consistent with other surveys $(1,2,3,4,5$,
$6,7,8,9,10,11,12,13,14,15)$. No deaths occurred due to colonic cancer or cardiac failure, probably due to the long-standing surveillance protocol adopted by both centres for several years. However, the study design was not able to clearly assess the role of colonoscopy in the prevention of colonic neoplasms. Although no deaths were due to a pump defect as a consequence of an extreme acromegalic cardiomyopathy, it cannot be excluded that cardiac hypertrophy may have emphasized the myocardial ischaemia, leading to cardiac failure. Overall, data from this study showed that therapies for acromegaly combined with a screening programme aimed at detecting and treating the commonest comorbidities lowered the risk of mortality to the level of the general population.

Age at diagnosis was a strong general risk factor associated with mortality. Deceased patients were older and were more compromised at diagnosis than survivors, in keeping with a large multicentre retrospective study (28) The general conditions of the patients at diagnosis were an important predictor of mortality; in fact, they influenced the outcome, which, in the most compromised patients, was unfavourable despite the control of acromegaly. In fact, in $41 \%$ of the deceased patients, acromegaly was controlled. As a matter of fact, among the 20 deceased patients, 12 were categorized as belonging to ASA Class 4; among the latter 12 patients, in $8(66.6 \%)$ patients, control of acromegaly was achieved. However, it should be noted that the ASA system, which we used to score the physical status of the 
Table 3 Clinical and biochemical features of the three treatment groups.

\begin{tabular}{|c|c|c|c|c|}
\hline Variables & Hx & $H x+S S A$ & SSA & $\boldsymbol{P}$ \\
\hline Sex: female, $n /$ total (\%) & $71 / 124(57.3)$ & $85 / 151(56.3)$ & $51 / 88(58.0)$ & $0.972^{\mathrm{a}}$ \\
\hline Age at diagnosis (years), mean \pm S.D. & $42.85 \pm 11.42$ & $39.71 \pm 11.17$ & $53.78 \pm 12.91$ & $0.000^{\mathrm{b}}$ \\
\hline Basal GH concentration at diagnosis $(\mu \mathrm{g} / \mathrm{l})$, mean \pm s.D. & $33.90 \pm 47.44$ & $43.10 \pm 73.11$ & $21.24 \pm 28.70$ & $0.018^{\mathrm{b}}$ \\
\hline IGF1 index at diagnosis, mean \pm S.D. & $2.44 \pm 1.07$ & $2.57 \pm 1.00$ & $2.82 \pm 1.36$ & $0.065^{\mathrm{b}}$ \\
\hline Estimated delay in diagnosis (years), mean \pm s.D. & $5.60 \pm 5.25$ & $6.41 \pm 6.33$ & $8.35 \pm 8.19$ & $0.010^{\mathrm{b}}$ \\
\hline Pituitary macroadenoma, $n /$ total (\%) & $85 / 122(69.7)$ & $124 / 145(85.5)$ & $45 / 86(52.3)$ & $0.000^{\mathrm{a}}$ \\
\hline Arterial hypertension, $n /$ total $(\%)$ & $53 / 124(42.7)$ & $41 / 151(27.2)$ & $42 / 88(47.7)$ & $0.002^{\mathrm{a}}$ \\
\hline Diabetes mellitus, $n /$ total (\%) & $21 / 124(16.9)$ & $39 / 151(25.8)$ & $24 / 88$ (27.3) & $0.118^{\mathrm{a}}$ \\
\hline Sleep apnoea, $n /$ total (\%) & $5 / 124(4.0)$ & $12 / 151(7.9)$ & $13 / 88(14.8)$ & $0.021^{\mathrm{a}}$ \\
\hline Left ventricular hypertrophy, $n /$ total (\%) & $38 / 109$ (34.9) & $56 / 144(38.9)$ & $41 / 84(48.8)$ & $0.139^{\mathrm{a}}$ \\
\hline Diastolic dysfunction, $n /$ total (\%) & $17 / 105(16.2)$ & $44 / 145(30.3)$ & $39 / 82(47.6)$ & $0.000^{\mathrm{a}}$ \\
\hline Hypopituitarism, n/total (\%) & $37 / 124(29.8)$ & $63 / 151(41.7)$ & 12/88 (13.6) & $0.000^{\mathrm{a}}$ \\
\hline Physical status (ASA scoring system), mean \pm s.D. & $2.35 \pm 0.70$ & $2.43 \pm 0.73$ & $2.77 \pm 0.85$ & $0.000^{\mathrm{b}}$ \\
\hline ASA Class $(n)$ & 115 & 141 & 86 & $0.000^{\mathrm{a}}$ \\
\hline ASA $1-2, n(\%)$ & $72(62.6)$ & $79(56.0)$ & $39(45.4)$ & \\
\hline ASA 3, $n(\%)$ & 37 (32.2) & $53(37.6)$ & $26(30.2)$ & \\
\hline ASA $4, n(\%)$ & $6(5.2)$ & $9(6.4)$ & $21(24.4)$ & \\
\hline Pituitary adenomectomy, $n /$ total (\%) & $124 / 124(100.0)$ & $151 / 151(100.0)$ & & \\
\hline Second pituitary surgery, $n /$ total $(\%)$ & $0 / 124(0.0)$ & $28 / 151(18.5)$ & $0 / 88(0.0)$ & $0.000^{\mathrm{a}}$ \\
\hline $\begin{array}{l}\text { Basal GH concentration at the last clinical visit }(\mu \mathrm{g} / \mathrm{l}) \text {, } \\
\text { mean } \pm \text { s.D. }\end{array}$ & $1.93 \pm 4.35$ & $6.40 \pm 12.37$ & $4.48 \pm 8.46$ & $0.001^{\mathrm{b}}$ \\
\hline IGF1 index at the last clinical visit, mean \pm s.D. & $0.71 \pm 0.33$ & $1.24 \pm 0.78$ & $1.34 \pm 1.12$ & $0.000^{\mathrm{b}}$ \\
\hline Deceased patients, $n /$ total (\%) & $3 / 124(2.4)$ & $4 / 151(2.6)$ & $10 / 88(11.4)$ & $0.007^{\mathrm{a}}$ \\
\hline Age of death (years), mean \pm S.D. & $73.33 \pm 6.35$ & $68.75 \pm 9.29$ & $69.00 \pm 11.57$ & $0.807^{b}$ \\
\hline
\end{tabular}

IGF1 was expressed as IGF1 index, representing the ratio of the observed serum IGF1 concentration to the upper IGF1 limit for the age; ASA: American Society of Anaesthesiologists physical status classification system ranged from 1 to 6 (25). Hx, pituitary adenomectomy; SSAs, somatostatin analogues. aSignificance was assessed using Fisher's exact test.

bSignificance was assessed using ANOVA.

patient, is partly subjective. The results of this study confirmed that uncontrolled acromegaly at the last clinical visit was an important predictor of mortality $(14,15)$. Both GH and IGF1 were associated with mortality in the univariate and multivariate analyses. A few reports have found IGF1 to be a predictor of mortality $(10,12,13)$, possibly due to the scanty data available for the analysis in previous studies $(1,14,15)$, at variance with our study, in which information on
IGF 1 concentration was available for more than $90 \%$ of the patients. More importantly, we demonstrated that IGF1 concentration at the last clinical visit reliably reflected the metabolic status of the patient as shown by the strong correlation with mean IGF1 concentration during the entire follow-up period. However, it should be underscored that $\mathrm{GH}$ concentration was measured using a competitive RIA in the previous years and using sensitive two-site non-competitive immunoassay

Table 4 Effect of therapies for acromegaly on mortality in univariate and multivariate Cox regression analyses.

\begin{tabular}{|c|c|c|c|c|}
\hline \multirow[b]{2}{*}{ Treatment groups $^{a}$} & \multicolumn{2}{|c|}{$\begin{array}{l}\text { Univariate analysis } \\
\text { (age-adjusted) }\end{array}$} & \multicolumn{2}{|c|}{$\begin{array}{l}\text { Multivariate } \\
\text { analysis }\end{array}$} \\
\hline & $\mathrm{HR}(95 \% \mathrm{Cl})$ & $P$ & $\mathrm{HR}(95 \% \mathrm{Cl})$ & $P$ \\
\hline \multicolumn{5}{|l|}{ All patients } \\
\hline Adenomectomy & 1 & & 1 & \\
\hline Adenomectomy and SSA therapy & $0.88(0.14-5.48)$ & 0.899 & $0.30(0.04-2.36)$ & 0.251 \\
\hline Primary SSA therapy & $1.94(0.45-8.24)$ & 0.371 & $3.24(0.61-17.33)$ & 0.169 \\
\hline All adenomectomy ${ }^{b}$ & 1 & & 1 & \\
\hline Primary SSA therapy & $2.02(0.54-7.59)$ & 0.300 & $5.52(1.06-28.77)$ & 0.043 \\
\hline \multicolumn{5}{|l|}{ Diabetic patients } \\
\hline All adenomectomy ${ }^{\mathrm{b}}$ & 1 & & 1 & \\
\hline Primary SSA therapy & $4.69(0.67-32.77)$ & 0.120 & $21.94(1.56-309.04)$ & 0.022 \\
\hline \multicolumn{5}{|l|}{ Non-diabetic patients } \\
\hline All adenomectomy ${ }^{\mathrm{b}}$ & 1 & & 1 & \\
\hline Primary SSA therapy & $0.73(0.11-5.03)$ & 0.751 & $1.30(0.04-38.09)$ & 0.881 \\
\hline
\end{tabular}

SSAs, somatostatin analogues; HR, hazard ratio.

a Multivariate analysis was adjusted for age at diagnosis, macroadenoma, hypopituitarism, ASA physical status as ASA Class, diabetes mellitus, arterial hypertension and IGF1 index at the last clinical visit.

'All adenomectomy: includes patients of the group 'adenomectomy' and those of the group 'adenomectomy and SSA therapy'. 


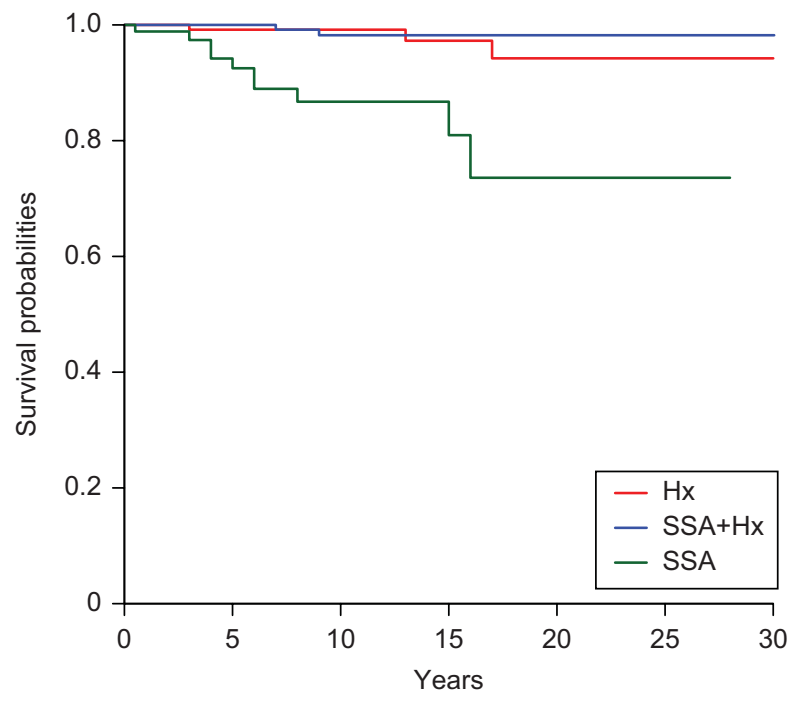

Figure 1 Survival of acromegalic patients over a 30-year period. Effect of different therapies on mortality: neurosurgery $(\mathrm{Hx})$, neurosurgery followed by external radiotherapy and/or somatostatin analogue therapy $(\mathrm{Hx}+\mathrm{SSA})$ and treatment with primary SSA therapy.

methods in the most recent years, thus carrying the risk of a potential bias of detection limit of serum $\mathrm{GH}$ concentration. Hypopituitarism was associated with mortality, as reported previously $(11,16,17)$. At variance with other reports (16), however, the extension of hypopituitarism (i.e. single vs total deficit), as an expression of the severity of pituitary damage, was associated with an increased mortality risk.

A relevant observation from our data is that patients treated with SSA therapy had a higher risk of death than those submitted to pituitary adenomectomy; it is worth noting that among patients treated with SSA therapy, only those with concomitant diabetes mellitus carried a significantly higher risk; however, differences between diabetic and non-diabetic patients may be limited by the low number of events. Our data may be limited, at least in part, by the relatively small number of deceased patients and by a selection bias; in fact, a relevant proportion of the most compromised patients, with a longer disease duration, an older age and a higher proportion of diabetes, received SSA therapy as the primary therapy. However, as a matter of fact, among patients with ASA score 4 treated with SSAs, mortality rate was $33.3 \%$, but only $13.3 \%$ in patients with ASA score 4 submitted to pituitary adenomectomy. Likewise, among patients with ASA score 3, a higher proportion of deaths occurred in those treated with SSAs $(12 \%)$ than in those treated with surgery $(4 \%)$. However, it is worth noting that the group of patients receiving SSA therapy alone had a higher risk of death than the whole group of patients submitted to pituitary adenomectomy, even after correction for several covariates, suggesting that, indeed, SSA therapy may be linked to an increased risk. Many reasons may contribute to explain this observation; patients treated with SSAs alone had higher IGF1 values at the last clinical visit than the others, in keeping with previous reports $(29,30)$, suggesting that an incomplete control of acromegaly activity may be detrimental for patients with diabetes mellitus, supporting a triangulation among the effects of SSA therapy, acromegaly and abnormalities of glucose metabolism on mortality.

It is interesting to note that the most compromised patients died irrespective of the achievement of control of disease, suggesting that the increased mortality risk in patients treated with primary SSA therapy is the result of several variables, including physical status, age and comorbidities, in addition to acromegaly activity. This finding underscores the concept that GH or IGF1 concentration (i.e. control of disease) should be considered an index of acromegaly and not a final target; the aims of therapy for acromegaly should be to achieve the disease control stopping the unrestricted effect of GHIGF 1 excess, on the one hand, and to treat comorbidities, on the other hand, which may persist independently of the control of acromegaly and may have a negative prognostic value. In addition, it is noteworthy that circulating IGF1 concentration mainly reflects the hepatic effects of GH and not necessarily gives information on extra-hepatic acromegaly (31); thus, it can be speculated that in the more compromised patients SSA therapy may not allow the achievement of a full control of acromegaly activity in extra-hepatic tissues, perpetuating harmful hyperstimulatory effects. In fact, differences have been reported in controlled patients who had undergone SSA therapy or those who had undergone pituitary surgery (32); notwithstanding similar IGF1 values, patients after surgery had a higher suppression of GH concentration and a better glycaemic profile after undergoing the OGTT than those in whom acromegaly was controlled with SSA therapy (32).

Although it has been reported that primary therapy with SSAs may ameliorate systemic complications in the short run, potentially affecting the clinical outcome of the patient (2), this is the first study to detail the effect of SSA therapy on mortality.

Radiotherapy was associated with an increased mortality risk, in keeping with other reports $(11,16$, $17,28)$. However, among the surgically treated patients, $71 \%$ of the deaths occurred among patients who were treated with irradiation because of macroadenoma, having locally more advanced tumour; thus, it is conceivable that the increased mortality risk was due to the underlying disease rather than to radiotherapy, suggesting that radiotherapy is an index of disease severity rather than a risk factor. As a matter of fact, causes of death of irradiated patients did not differ from those of patients who did not receive external radiotherapy, reinforcing the concept that radiotherapy was not associated with a specific cause of death. However, it should be underlined that radiotherapy was performed mainly using enlarged irradiation fields; 
thus, whether concomitant side effects of radiotherapy may have contributed to mortality cannot be excluded.

The main strengths of this study are that data, retrieved from clinical records, were prospectively collected in two referral centres. Information on general risk factors as well as on other clinical and biochemical findings was available for the large majority of patients.

Limitations are mainly due to the observational nature of the study, as had occurred in other studies on mortality, and the small number of deceased patients. In addition, although comparison among the therapeutic groups was made after correction for several covariates, it cannot be ruled out that other covariates not included in the study, for example, smoking habits and duration of comorbidities, as well therapies for comorbidities, may not have played a role; in addition, even with statistical correction for potential confounders, statistical analysis might not fully remove the effect of these significant confounders on mortality.

These data suggest that the mortality rate of patients with acromegaly could be lowered to the level of the general population through a multidisciplinary approach based on disease control and treatment of comorbidities. Curative pituitary adenomectomy seems to be the most favourable treatment for acromegalic patients.

\section{Declaration of interest}

The authors declare that no competing interests exist; F Bogazzi, G Lombardi, E Martino and A Colao received unconditional research funding from Ipsen, Novartis and Pfizer. All the other authors declare no support from any organization for the submitted work; no financial relationships with any organization that might have an interest in the submitted work in the previous 3 years; and no other relationships or activities that could appear to have influenced the submitted work.

\section{Funding}

This work was partially supported by grants from the University of Pisa (Fondi d'Ateneo) to F Bogazzi and E Martino.

\section{Author contribution statement}

All authors had access to all the study data, analysed and interpreted the data, and reviewed, edited and approved the report for publication. F Bogazzi, G Rossi, A Colao and E Martino designed the study. S Del Sarto and G Rossi undertook the statistical analysis.

\section{Acknowledgements}

We thank Fondazione Peretti (Rome, Italy) for technical support.

\section{References}

1 Kauppinen-Makelin R, Sane T, Reunanen A, Valimaki MJ, Niskanen L, Markkanen H, Loyttyniemi E, Ebeling T, Jaatinen P, Laine $\mathrm{H}$ et al. A nationwide survey of mortality in acromegaly. Journal of Clinical Endocrinology and Metabolism 200590 4081-4086. (doi:10.1210/jc.2004-1381)
2 Colao A, Ferone D, Marzullo P \& Lombardi G. Systemic complications of acromegaly: epidemiology, pathogenesis, and management. Endocrine Reviews 200425 102-152. (doi:10.1210/ er.2002-0022)

3 Holdaway IM, Rajasoorya CR, Gamble GD \& Stewart AW. Longterm treatment outcome in acromegaly. Growth Hormone $\mathcal{E}$ IGF Research 200313 185-192. (doi:10.1016/S1096-6374(03) 00030-3)

4 Melmed S. Acromegaly pathogenesis and treatment. Journal of Clinical Investigation 2009119 3189-3202. (doi:10.1172/ JCI39375)

5 Wright AD, Hill DM, Lowy C \& Fraser TR. Mortality in acromegaly. Quarterly Journal of Medicine 197039 1-16.

6 Alexander L, Appleton D, Hall R, Ross WM \& Wilkinson R. Epidemiology of acromegaly in the Newcastle region. Clinical Endocrinology 198012 71-79. (doi:10.1111/j.1365-2265.1980. tb03135.x)

7 Bengtsson BA, Eden S, Ernest I, Oden A \& Sjogren B. Epidemiology and long-term survival in acromegaly. A study of 166 cases diagnosed between 1955 and 1984. Acta Medica Scandinavica 1988 223 327-335. (doi:10.1111/j.0954-6820.1988.tb15881.x)

8 Rajasoorya C, Holdaway IM, Wrightson P, Scott DJ \& Ibbertson HK. Determinants of clinical outcome and survival in acromegaly. Clinical Endocrinology $1994 \mathbf{4 1}$ 95-102. (doi:10.1111/j.13652265.1994.tb03789.x)

9 Orme SM, McNally RJ, Cartwright RA \& Belchetz PE. Mortality and cancer incidence in acromegaly: a retrospective cohort study. United Kingdom Acromegaly Study Group. Journal of Clinical Endocrinology and Metabolism $1998 \quad 83 \quad 2730-2734$. (doi:10.1210/jc.83.8.2730)

10 Swearingen B, Barker FG II, Katznelson L, Biller BM, Grinspoon S, Klibanski A, Moayeri N, Black PM \& Zervas NT. Long-term mortality after transsphenoidal surgery and adjunctive therapy for acromegaly. Journal of Clinical Endocrinology and Metabolism 1998 83 3419-3426. (doi:10.1210/jc.83.10.3419)

11 Ayuk J, Clayton RN, Holder G, Sheppard MC, Stewart PM \& Bates AS. Growth hormone and pituitary radiotherapy, but not serum insulin-like growth factor-I concentrations, predict excess mortality in patients with acromegaly. Journal of Clinical Endocrinology and Metabolism 200489 1613-1617. (doi:10.1210/jc.2003-031584)

12 Biermasz NR, Dekker FW, Pereira AM, van Thiel SW, Schutte PJ, van Dulken H, Romijn JA \& Roelfsema F. Determinants of survival in treated acromegaly in a single center: predictive value of serial insulin-like growth factor I measurements. Journal of Clinical Endocrinology and Metabolism 200489 2789-2796. (doi:10.1210/jc.2003-032041)

13 Holdaway IM, Rajasoorya RC \& Gamble GD. Factors influencing mortality in acromegaly. Journal of Clinical Endocrinology and Metabolism 2004 89 667-674. (doi:10.1210/jc.2003-031199)

14 Holdaway IM, Bolland MJ \& Gamble GD. A meta-analysis of the effect of lowering serum levels of GH and IGF-I on mortality in acromegaly. European Journal of Endocrinology 2008159 89-95. (doi:10.1530/EJE-08-0267)

15 Dekkers OM, Biermasz NR, Pereira AM, Romijn JA \& Vandenbroucke JP. Mortality in acromegaly: a metaanalysis. Journal of Clinical Endocrinology and Metabolism 200893 61-67. (doi:10.1210/jc.2007-1191)

16 Sherlock M, Reulen RC, Alonso AA, Ayuk J, Clayton RN, Sheppard MC, Hawkins MM, Bates AS \& Stewart PM. ACTH deficiency, higher doses of hydrocortisone replacement, and radiotherapy are independent predictors of mortality in patients with acromegaly. Journal of Clinical Endocrinology and Metabolism 200994 4216-4223. (doi:10.1210/jc.2009-1097)

17 Tomlinson JW, Holden N, Hills RK, Wheatley K, Clayton RN, Bates AS, Sheppard MC \& Stewart PM. Association between premature mortality and hypopituitarism. West Midlands Prospective Hypopituitary Study Group. Lancet 2001357 425-431. (doi:10.1016/S0140-6736(00)04006-X)

18 Colao A \& Ghigo E. The manifesto A.L.I.C.E. (Acromegaly primary medical treatment Learning and Improvement with Continuous 
Medical Education) study group one year later: what to keep and what to amend? Journal of Endocrinological Investigation $2007 \mathbf{3 0}$ 903-906.

19 Melmed S, Colao A, Barkan A, Molitch M, Grossman AB, Kleinberg D, Clemmons D, Chanson P, Laws E, Schlechte J et al. Guidelines for acromegaly management: an update. Journal of Clinical Endocrinology and Metabolism 2009 94 1509-1517. (doi:10.1210/jc.2008-2421)

20 Giustina A, Chanson P, Bronstein MD, Klibanski A, Lamberts S, Casanueva FF, Trainer P, Ghigo E, Ho K \& Melmed S. A consensus on criteria for cure of acromegaly. Journal of Clinical Endocrinology and Metabolism 2010 95 3141-3148. (doi:10.1210/jc.2009-2670)

21 Mancia G, De Backer G, Dominiczak A, Cifkova R, Fagard R, Germano G, Grassi G, Heagerty AM, Kjeldsen SE, Laurent S et al. Guidelines for the management of arterial hypertension: The Task Force for the Management of Arterial Hypertension of the European Society of Hypertension (ESH) and of the European Society of Cardiology (ESC). Journal of Hypertension $2007 \mathbf{2 5}$ 1105-1187. (doi:10.1097/HJH.0b013e3281fc975a)

22 Alberti KG \& Zimmet PZ. Definition, diagnosis and classification of diabetes mellitus and its complications. Part 1: diagnosis and classification of diabetes mellitus provisional report of a WHO consultation. Diabetic Medicine 199815 539-553. (doi:10.1002/(SICI)1096-9136(199807)15:7< 539::AID-DIA668 $>3.0 . \mathrm{CO} ; 2-\mathrm{S})$

23 National Cholesterol Education Program (NCEP) Expert Panel on Detection, Evaluation, and Treatment of High Blood Cholesterol in Adults (Adult Treatment Panel III). Third Report of the National Cholesterol Education Program (NCEP) Expert Panel on Detection, Evaluation, and Treatment of High Blood Cholesterol in Adults (Adult Treatment Panel III) final report. Circulation 2002106 3143-3421.

24 Mak PH, Campbell RC \& Irwin MG. The ASA physical status classification: inter-observer consistency. Anaesthesia and Intensive Care $200230633-640$.

25 Wolters U, Wolf T, Stutzer H \& Schroder T. ASA classification and perioperative variables as predictors of postoperative outcome. British Journal of Anaesthesia 199677 217-222. (doi:10.1093/ bja/77.2.217)
26 Breslow NE \& Day NE. Statistical methods in cancer research. In The Analysis of Case-control Studies, Vol 1, pp 5-338. Lyon, France: IARC Scientific Publications, 1980.

27 Breslow NE \& Day NE. Statistical methods in cancer research. In The Design and Analysis of Cohort Studies, Vol 2, pp 1-406. Lyon, France: IARC Scientific Publications, 1987.

28 Arosio M, Reimondo G, Malchiodi E, Berchialla P, Borraccino A, De Marinis L, Pivonello R, Grottoli S, Losa M, Cannavò S et al. Predictors of morbidity and mortality in acromegaly: an Italian survey. European Journal of Endocrinology 2012167 189-198. (doi:10.1530/EJE-12-0084)

29 Bihan H, Espinosa C, Valdes-Socin H, Salenave S, Young J, Levasseur S, Assayag P, Beckers A \& Chanson P. Longterm outcome of patients with acromegaly and congestive heart failure. Journal of Clinical Endocrinology and Metabolism 200489 5308-5313. (doi:10.1210/jc.2004-0821)

30 Petersenn S, Buchfelder M, Reincke M, Strasburger CM, Franz H, Lohmann R, Quabbe HJ \& Plockinger U. Results of surgical and somatostatin analog therapies and their combination in acromegaly: a retrospective analysis of the German Acromegaly Register. European Journal of Endocrinology 2008159 525-532. (doi:10.1530/EJE-08-0498)

31 Neggers SJ, Kopchick JJ, Jorgensen JOL \& van der Lely AJ. Hypothesis: extra-hepatic acromegaly: a new paradigm? European Journal of Endocrinology $2011 \mathbf{1 6 4} 11-16$. (doi:10.1530/EJE10-0969)

32 Rubeck KZ, Madsen M, Andreasen CM, Fisker S, Frystyk J \& Jørgensen JOL. Conventional and novel biomarkers of treatment outcome in patients with acromegaly: discordant results after somatostatin analog treatment compared with surgery. European Journal of Endocrinology 2010163 717-722. (doi:10.1530/ EJE-10-0640)

Received 28 February 2013

Revised version received 21 June 2013

Accepted 3 July 2013 